\title{
Michel Garcia (ED.), CRÓNICA ANÓNIMA DE ENRIQUE III DE CASTILLA (1390-1391): EDICIÓN COMENTADA DEL MS. II/755 DE LA REAL BIBLIOTECA. Marcial Pons, Madrid, 2013, 194 PÁGinas. ISBN: 9788415963042.
}

\author{
Francisco BAUTISTA \\ Universidad de Salamanca
}

En este libro, Michel Garcia ofrece una edición y estudio de una versión netamente diferenciada y hasta ahora desconocida de la Crónica de Enrique III de Pero López de Ayala. Se trata de un texto fragmentario, que cubre únicamente el comienzo del reinado de Enrique III, desde la muerte de su padre Juan I en octubre de 1390 hasta el acuerdo para celebrar cortes en Burgos (1392), algo que tuvo lugar en agosto-septiembre de 1391. Así pues, poco menos de un año de relato, que queda circunscrito a los turbulentos primeros meses de la minoría de Enrique III. A pesar de su reducida extensión, de que se trata de un texto íntimamente ligado a la crónica de López de Ayala (no de una crónica independiente) y de que se conserva en un manuscrito único de la segunda mitad del siglo XVI, tardío por lo tanto, es mérito del editor haber sabido apreciar su valor, que reside no solo en ofrecer nuevos datos y nuevas perspectivas sobre los hechos de los que trata, sino también en haberse redactado con cercanía al reinado de Enrique III, por lo que viene a ocupar un lugar fundamental entre las fuentes narrativas de su época.

Michel Garcia proporciona una cuidada e intachable transcripción del manuscrito, de no fácil lectura, incluye una detallada descripción codicológica del mismo y completa su trabajo con un comentario filológico, literario e histórico. A propósito de la edición, Garcia ha optado por mantener las grafías del manuscrito, aunque incluye puntuación y mayúsculas. Se trata de una decisión plenamente justificada, al tratarse de una edición de un único manuscrito, y que en nada dificulta la lectura del texto. En una hoja de guarda del códice que preserva el texto, se aclara que este fue "trasladado" a partir de unos "papeles viejos" cuando estos pasaron de Burgos a Valladolid. Se trata, pues, de una copia de un códice medieval, que como expone convincentemente el editor, era probablemente una copia de trabajo, es decir, un manuscrito con algunos rasgos de borrador. El más importante de ellos tiene que ver con la doble redacción del comienzo del capítulo 10, que puede leerse en dos lugares del estudio (p. 26 y 162-163). Así pues, este nuevo texto, además de la luz que arroja sobre la minoría de Enrique III, proporciona nuevos indicios sobre la escritura de la historia en la Baja Edad Media. 
A la edición le sigue un comentario filológico, literario e histórico, que pone de manifiesto la singularidad y el interés del texto. Garcia confronta la versión por él editada con la Crónica de Enrique III, y muestra cómo la primera es consistentemente más amplia, con un mayor desarrollo del relato, con más precisiones y valoraciones de los hechos, y a menudo con nueva información. Entre las novedades más importantes, el editor destaca un capítulo añadido que trata del pogrom sevillano de 1391, que permite conocer un poco mejor este importante hecho, sobre el que existe escasa documentación. Garcia señala también la tendencia en este fragmento cronístico a integrar de forma más amplia los discursos de los personajes o los documentos, algo que se traduce en un caso en la inclusión de una carta del arzobispo de Toledo Pedro Tenorio, que no figura en la obra de Ayala (p. 69-70). Además, el redactor tiende a valorar los hechos, ofreciendo una perspectiva crítica sobre la minoría de Enrique III. Pongamos algunos ejemplos: comenta que poseer y mandar está en el ánimo de los hombres, "mayormente el de los españoles" (p. 35), habla del efecto pernicioso que para el reino tienen los rumores sobre las disensiones en la corte (p. 55), responsabiliza a Pedro Tenorio del aumento de las alteraciones en Castilla (p. 102), o juzga duramente a Fadrique, duque de Benavente, a quien acusa de una ambición desmedida (p. 112).

Además de "enjuiciar la dimensión política de los sucesos", Garcia señala que la nueva redacción se caracteriza "por una atención a los detalles de los acontecimientos" ( $p$. 168). Esto se aprecia en la descripción de las embajadas, donde se dan pormenores de tipo ceremonial ausentes en el texto de Ayala, y en otros muchos pasos en los que encontramos una mayor precisión en los nombres y una caracterización más amplia de los movimientos de la corte (véase, por ejemplo, la narración sobre el traslado del rey a Valladolid, p. 114-115). Esto tiene también implicaciones literarias, señaladas agudamente por Garcia, en la medida en que esta nueva redacción parece representar una corriente historiográfica más personal, más dramática y más detallista, en la que la ambientación del relato y la caracterización de los individuos son elementos cada vez más importantes. En este sentido, esta versión anuncia o se encuentra en sintonía con algunas tendencias dominantes en la historiografía castellana del siglo XV.

La riqueza y el interés del texto rescatado por García deberían ser acicate para el estudio de la Crónica de Enrique III de Ayala, para el que carecemos todavía de un estudio de su transmisión manuscrita y también de una edición crítica. Justamente esta situación otorga una posición paradójica al libro aquí reseñado, en la medida en que contamos ahora con una edición impecable de una "versión" de la crónica de Ayala, conservada en un manuscrito único, pero no disponemos aún de un texto fiable de la obra misma de Ayala. Tal panorama implica necesariamente que algunos análisis deban tomarse aún como provisionales. A este respecto, es previsible que un mejor conocimiento de la tradición de la Crónica de Enrique III pueda contribuir a una valoración más precisa de las variaciones de la redacción editada por Garcia, lo que a su vez habrá de arrojar nuevos datos para su contextualización. El editor ha confrontado el texto que presenta no solo con la edición de la crónica de Ayala, que remonta al siglo XVIII (no ha utilizado, sin embargo, la edición de Constance L. Wilkins y Heanon M. Wilkins, publicada en 
1992), sino también con algunos manuscritos, pero en ausencia de un trabajo específico sobre estos se trata solo de un primer paso, que le ha permitido, no obstante, salvar algunos equívocos que hubiera ocasionado el cotejo exclusivo con el texto impreso.

No debe sorprender, por todo ello, que la consideración de algunos aspectos haya de permanecer, a mi juicio, abierta. Michel Garcia se decanta por la hipótesis de que el texto que edita fue redactado con posterioridad a la muerte de Ayala, y propone atribuirlo a Álvar García de Santa María, quien en 1421 fue designado cronista regio, y quien podría haberlo compuesto antes de tal fecha como una suerte de preparación para ese cargo. Esta atribución descansa fundamentalmente en el hecho de que el modelo del manuscrito que conserva el texto procediera de Burgos, de donde era Álvar García. Sin embargo, sabemos por este mismo autor que, cuando fue nombrado cronista, el rey ordenó a los familiares del anterior oficial que le entregaran todos los papeles que éste había dejado que tuvieran que ver con la historia del reino. ¿No podría encontrarse tal manuscrito entre ellos? Es más, ¿no podría haberse producido un mandato similar tras la muerte de López de Ayala?

Algunos datos en el texto de esta nueva versión sugieren de hecho que fue redactada durante el reinado de Enrique III. Así, se habla siempre de este como quien reina en el momento presente, en pasajes que carecen de correspondencia con el texto de Ayala: "Enrrique, su abuelo deste rrey don Enrrique terzero que agora rreyna" (p. 34), "Enrrique [segundo], agüelo del que agora rreyna" (p. 34) "este rrey don Enrrique, que agora rreyna" (p. 102; véase también p. 96). Es poco probable que una reescritura del texto elaborada después de la muerte de Enrique III hubiera introducido estas referencias. Otros aspectos se explicarían mejor, a mi juicio, desde esta perspectiva. Así, los detalles sobre las embajadas apuntan a un testigo presencial, como también la inclusión de nombres de personajes o de lugares que no figuran en el texto de Ayala. Y si es cierto que esta versión se compuso en época de Enrique III, ello no solo acentuaría su interés histórico, sino también literario, en la medida en que el único candidato como su autor sería el propio Ayala, quien murió en 1407, poco después de que lo hiciera Enrique III (1406). Sería necesario explorar con mayor detenimiento esta posibilidad, que nos situaría ante un nuevo texto de Ayala y ante un caso de doble redacción autorial de la Crónica de Enrique III, análogo al que encontramos para la Crónica de Pedro I y Enrique II.

Sirvan estas últimas apreciaciones como muestra del interés y de la relevancia que presenta la versión editada por Michel Garcia. Es muy probable que un mejor conocimiento de la transmisión manuscrita de la Crónica de Enrique III, un análisis minucioso de las referencias históricas propias de la nueva versión, y una confrontación con la biografía de los años finales de Ayala arrojen nueva luz sobre este texto y contribuyan a contextualizarlo, tal vez revelando incluso su autoría, por ahora incierta. Por todo ello, este libro abre nuevas e inéditas vías de investigación sobre la última de las crónicas de Ayala, al tiempo que el texto que ofrece se erige como una fuente esencial sobre la minoría de Enrique III. Conservado por ahora en un manuscrito único, la edición de Garcia probablemente permita también identificar algún otro ejemplar más, tal vez 
entre los numerosos manuscritos catalogados bajo el título de Crónica de Enrique III, de muchos de los cuales carecemos de indicaciones precisas sobre su contenido.

En suma, por su rigurosa edición de un texto hasta ahora desconocido, próximo a los hechos que narra, y de innegable valor histórico y literario, y por las nuevas perspectivas que abre sobre la cronística bajomedieval y sobre la minoría de Enrique III, expuestas con claridad en el estudio, este libro constituye no solo una aportación decisiva e imprescindible, sino que está llamado a impulsar otras investigaciones sobre la última crónica de Pero López de Ayala y sobre la evolución del género en la Baja Edad Media. 